\title{
RESEARCH
}

Open Access

\section{Chia (Salvia hispanica)-supplemented diet ameliorates non-alcoholic fatty liver disease and its metabolic abnormalities in humans}

Aida Medina-Urrutia', Angel R. Lopez-Uribe ${ }^{1}$, Mohamed El Hafidi², Maria del Carmen González-Salazar', Rosalinda Posadas-Sánchez ${ }^{1}$, Esteban Jorge-Galarza' ${ }^{1}$, Leonardo del Valle-Mondragón ${ }^{3}$ and Juan G. Juárez-Rojas ${ }^{1 *}$ (D)

\begin{abstract}
Background: Non-alcoholic fatty liver disease (NAFLD) is a public health problem lacking an approved pharmacological treatment. Omega-3 fatty acids have shown to reverse NAFLD. Chia is a seed rich in a-linolenic acid (ALA), antioxidants, and fiber; therefore, it could be useful to treat NAFLD.

Methods: In a single arm experimental design study, the effect of $25 \mathrm{~g} /$ day of milled chia was assessed in 25 patients with NAFLD. After two weeks of dietary stabilization (basal condition) and eight weeks of a chiasupplemented isocaloric diet, liver:spleen attenuation index and visceral abdominal fat (VAF) were measured by computed tomography. Lipids, lipoproteins, free fatty acids (FFA), and ALA plasma concentrations were also determined.

Results: Dietary chia supplementation induced an increase in plasma ALA concentration (75\%) and dietary fiber (55\%) consumption. After chia supplementation, VAF (9\%), body weight (1.4\%), total cholesterol (2.5\%), non-high density lipoprotein cholesterol (3.2\%), and circulating FFA (8\%) decreased. Furthermore, NAFLD regressed in 52\% of the treated patients $(P<0.05$ for all).

Conclusions: The results of the present study show that $25 \mathrm{~g} /$ day of milled chia ameliorates NAFLD. Chia is an accessible vegetal source of omega-3 fatty acids, antioxidants, and fiber, which could have the potential to prevent metabolic abnormalities in NAFLD patients. Considering that there is no pharmacological treatment approved for NAFLD, the findings of the present study suggest that a chia-supplemented diet could be an innovative alternative to control this disease.
\end{abstract}

Retrospectively registered: https://clinicaltrials.gov/show/NCT03942822

Keywords: Non-alcoholic fatty liver disease, Chia, Visceral abdominal fat, Cardiometabolic risk

\footnotetext{
*Correspondence: gaboyk2@gmail.com

'Departamento de Endocrinología, Juan Badiano 1, Col. Sección XVI, Tlalpan, Mexico City, Mexico

Full list of author information is available at the end of the article
}

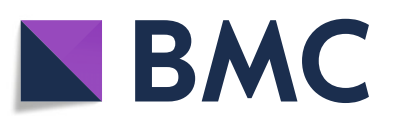

(- The Author(s). 2020 Open Access This article is licensed under a Creative Commons Attribution 4.0 International License, which permits use, sharing, adaptation, distribution and reproduction in any medium or format, as long as you give appropriate credit to the original author(s) and the source, provide a link to the Creative Commons licence, and indicate if changes were made. The images or other third party material in this article are included in the article's Creative Commons licence, unless indicated otherwise in a credit line to the material. If material is not included in the article's Creative Commons licence and your intended use is not permitted by statutory regulation or exceeds the permitted use, you will need to obtain permission directly from the copyright holder. To view a copy of this licence, visit http://creativecommons.org/licenses/by/4.0/. The Creative Commons Public Domain Dedication waiver (http://creativecommons.org/publicdomain/zero/1.0/) applies to the data made available in this article, unless otherwise stated in a credit line to the data. 


\section{Introduction}

Parallel to the obesity epidemic, non-alcoholic fatty liver disease (NAFLD) prevalence has markedly increased during the last years [1]. Recent epidemiological studies have found that one of three adults has NAFLD, which has been associated with a cluster of metabolic abnormalities $[1,2]$. As noted, poor-quality diets characterized by high fructose content and deficient omega-3 fatty acids consumption, scarce physical activity, excess in visceral abdominal fat (VAF), insulin resistance, and genetic susceptibility have shown to be relevant determinants for this hepatic disorder [2-4]. It has been observed that type 2 diabetes mellitus (T2DM) and coronary artery disease (CAD) are the most frequent complications of NAFLD; nonetheless, it can also progress to cirrhosis and hepatic carcinoma $[1,2]$. Hence, NAFLD is considered a multisystemic disease and a public health problem [1].

Although no drug has been specifically approved for the treatment of NAFLD, recent studies indicate that dietary supplementation with marine-origin omega- 3 fatty acids (eicosapentaenoic acid [EPA]/docosahexaenoic acid [DHA]) and the Mediterranean-style diet are useful to treat NAFLD $[4,5]$. EPA and DHA reduce the intrahepatic fat content and improve the metabolic profile observed in these patients, even in the absence of caloric restriction diets [5]. However, due to the socioeconomic and sociocultural characteristics of some populations, the consumption of these foods is complicated, increasing the interest in searching for alternatives of omega-3 fatty acids from vegetal sources [6].

Therapies that focus on the use of functional foods, rich in a variety of phytochemicals, mono/polyunsaturated fatty acids, antioxidants, minerals, and fiber, have shown antioxidant, anti-inflammatory, and lipid-lowering effects $[7,8]$, which could be useful in patients with NAFLD [6]. Chia seed (Salvia hispanica) is the richest vegetal source of omega 3-fatty acids, antioxidants, and fiber [9]. Although some animal models have suggested that chia could be used as an alternative to reduce intrahepatic fat content $[10,11]$, its effect on NAFLD patients has not been studied yet. Hence, the objective of the present study was to analyze whether the consumption of an isocaloric diet supplemented with chia could ameliorate NAFLD, VAF, and metabolic abnormalities in NAFLD patients.

\section{Materials and methods}

\section{Participants}

Participants were chosen from the control group of the Genetics of Atherosclerotic Disease (GEA, for its initials

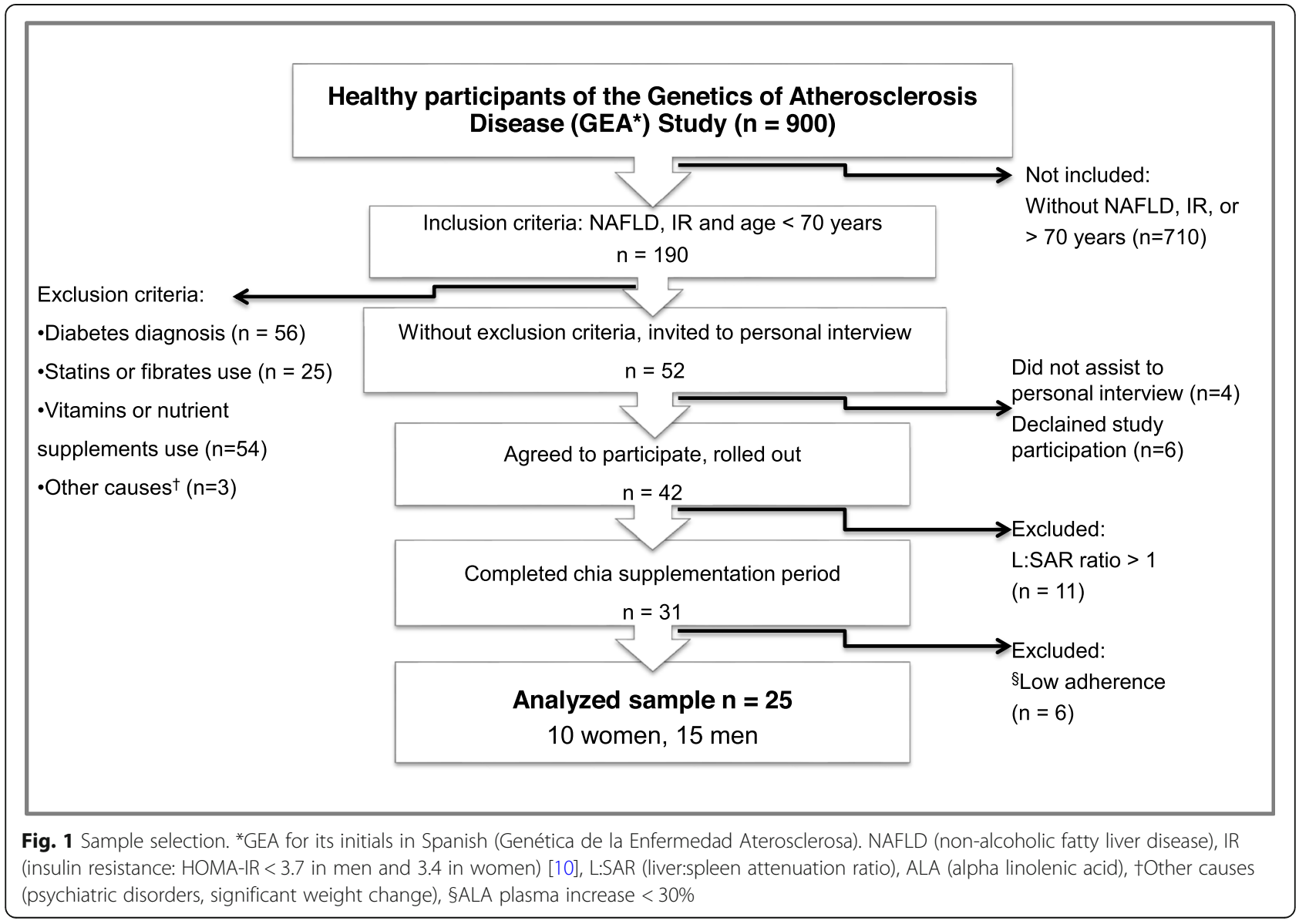


in Spanish) study, performed at the Instituto Nacional de Cardiología Ignacio Chávez in Mexico City, Mexico (Fig. 1). Eligible subjects were those younger than 70years (30-69 years) with NAFLD diagnosis confirmed by computed tomography $(\mathrm{CT})$ imaging and with insulin resistance assessed by the homeostatic model assessment insulin resistance index (HOMA-IR) [12]. Exclusion criteria were previous diabetes diagnosis, use of hypoglycemic or hypolipidemic medications, unstable body weight (variation $>5 \%$ within the preceding 3 -month period), consumption of vitamins, herbal or food supplements, gastrointestinal, renal, or hepatic diseases, and the presence of eating, psychiatric or cognitive disorders that would hurdle the understanding of the study instructions and their compliance. Candidates that accepted to participate in the study signed a written informed consent form prior to completing any assessment.

The experimental protocol was conducted according to the ethical guidelines of the 1975 Declaration of Helsinki, it was approved by the Research and Ethics Committee of the Instituto Nacional de Cardiología Ignacio Chavez (No. 16-980), and was retrospectively registered at clinical trials.gov (NCT03942822).

\section{Nutritional intervention and food intake evaluation}

To know the current eating habits, including total energy, macronutrients and fiber intake, 24-h dietary recalls were applied on the first visit by a trained nutritionist. As previously recommended, two weekdays and one day of the weekend were considered for the recalls [13]. To standardize macronutrient dietary composition, two weeks before starting chia supplementation, each patient was interviewed by the nutritionist aimed at designing and explaining his/her isocaloric diet (30\% of total energy as fat, $15 \%$ of energy as protein, and $55 \%$ of energy as carbohydrate) to be followed during the study. After dietary standardization, each patient was provided monthly with 30 sachets of $25 \mathrm{~g}$ of chia seeds. In the first month, a 4-oz glass jar blender (Oster ${ }^{\bullet}$ Classic Series Kitchen) was provided to mill chia seeds, and the patients were instructed to mill one sachet per day, pointing out the relevance of consuming the milled seed from breakfast through lunch, but always before 6:00 p.m. It was recommended to intake chia with water, salads, or cold dishes. To foster treatment adherence and record adverse events (appetite loss, constipation, diarrhea, flatulence and nausea, allergy or chia intolerance), patients were contacted once a week during the intervention. Since ALA is an essential fatty acid that can only be given through the diet, a higher than $30 \%$ increase in plasma ALA concentration was considered an indicator of appropriate compliance of chia consumption [14]. In addition, in patients who had an increase in ALA equal or higher than $30 \%$, the adherence to seed consumption was calculated as the median of the empty chia sachets returned by the patients. Thirty empty sachets were considered as $100 \%$ compliance. Anthropometric, diet evaluation, laboratory test, and computed tomography studies were made after dietary standardization (basal condition), and after 8 weeks of chia supplementation. Patients were advised to maintain dietary recommendations and their usual level of physical activity throughout the study.

\section{Anthropometric evaluation}

Anthropometric measurements were obtained according to the International Society for the Advancement of Kinanthropometry (ISAK) regulations, by a certified nutritionist. Weight and height of the patients were recorded before 8:00 a.m. in fasting conditions; participants were required to remove shoes and all outer cloths and heavy pocket items. A digital scale (Soehnle Professional Design 7830, Leifheit, Nassau, Germany), and a SECA 220 wall stadiometer (seca GMBH and Co. KG, Hamburg, Germany) were used, with an accuracy of $0.1 \mathrm{~kg}$ and $0.1 \mathrm{~cm}$, respectively. Body mass index (BMI) was calculated as weight $(\mathrm{kg}) /$ height $\left(\mathrm{m}^{2}\right)$. Waist circumference was measured with a non-stretch tape (Lufkin W606PM $6 \mathrm{~mm} \times 2 \mathrm{~m}$, Zapopan, Jal. Mexico). The measurement was made in duplicate, with the patient without clothes around the waist, at the midway between the lowest rib and the iliac crest, measures were averaged; however, a third measurement was taken if they differed more than $0.5 \mathrm{~cm}$.

\section{Laboratory tests}

After 10-h fasting and $20 \mathrm{~min}$ in sitting position, venous blood was collected in assay tubes without anticoagulant and in tubes with K2-EDTA $(1.8 \mathrm{mg} / \mathrm{mL})$. Glucose, total cholesterol (TC), triglyceride (TG), high-density lipoprotein cholesterol (HDL-C), alanine aminotransferase (ALT), aspartate aminotransferase (AST), gamma glutamyl transpeptidase (GGT), and uric acid (UA) concentrations were determined using direct standard enzymatic colorimetric methods (Roche Diagnostics, Mannheim, Germany), in a COBAS c311 analyzer. Lowdensity lipoprotein cholesterol (LDL-C) concentration was estimated using the DeLong formula [15]. The reproducibility and precision of these determinations were assessed by the Center for Disease Control and Prevention Lipids Standardization Program (LSP-CDC, Atlanta, GA, USA). Free fatty acids (FFA) were determined in plasma by an enzymatic-colorimetric assay (Wako Diagnostics, Chuo-Ku Osaka, Japan).

Liver enzyme values were considered high when ALT, AST, or GGT were $\geq$ percentile 75 (ALT: $23 \mathrm{U} / \mathrm{L}$ and 30 U/L, AST: $27 \mathrm{U} / \mathrm{L}$ and $29 \mathrm{U} / \mathrm{L}, \mathrm{GGT}: 21 \mathrm{U} / \mathrm{L}$ and $28 \mathrm{U} / \mathrm{L}$, for women and men; respectively). These cut-off values 
were obtained from 101 men and 180 women in the GEA study, without obesity and normal lipid, glucose, and blood pressure values.

\section{Plasma total fatty acid (TFA) analysis}

To $100 \mu \mathrm{L}$ of plasma, $50 \mu \mathrm{L}$ of a solution of heptadecanoic acid (C17:0, Sigma Co., St. Louis, MO, USA) (1 mg/ $\mathrm{mL}$ ) in chloroform was added as an internal standard. All solvents and chemicals were analytical grade from J. T Baker (Avantor Performance Materials, Central Valley, PA, USA). Plasma lipids were subsequently extracted three times with a chloroform:methanol $(1: 2 v / v)$ mixture, by vigorous vortexing for $1 \mathrm{~min}$, according to the Folch's method [16]. After centrifugation, the organic layer was collected, combined, and the solvent evaporated at $40{ }^{\circ} \mathrm{C}$ under a nitrogen stream. Fatty acid transmethylation was immediately carried out at $80^{\circ} \mathrm{C}$, in a 2mL mixture of methanol: $\mathrm{H}_{2} \mathrm{SO}_{4}$ (2\%). Fatty acid methyl esters were extracted three times with $2 \mathrm{~mL}$ of $\mathrm{n}$-hexane, which was separated and dried under nitrogen. The dry residue was dissolved in $50 \mu \mathrm{L}$ of $\mathrm{n}$-hexane, and $1 \mu \mathrm{L}$ was analyzed in a Shimadzu GC-8A gas chromatograph equipped with a flame ionization detector (Shimadzu, Kyoto, Japan) and an SP2330 capillary column of $25 \mathrm{~m}$ length and $0.25 \mathrm{~mm}$ internal diameter (SUPELCO, Bellefonte, PA, USA). Fatty-acid peaks were identified by using the Supelco 37 component FAME Mix (CRM47885, SUPELCO, Bellefonte, PA, USA). A plasma control sample was run in each extraction assay; ALA inter-assay coefficient variation was lower than $13 \%$.

\section{Chia's fatty acid composition}

The chia seeds were milled and analyzed for fatty acid content according to the AOAC [17] procedures, modified in our laboratory. Briefly, $100 \mathrm{mg}$ of the milled seeds in the presence of $100 \mu \mathrm{g}$ of heptadecanoic acid (C17:0), as internal standard, were stirred in $2 \mathrm{~mL}$ of a mixture of chloroform/methanol $(2: 1, v / v)$, containing $0.002 \%$ of butylated hydroxytoluene (BHT) as antioxidant, in an ice bed overnight. At the end of this period, $1 \mathrm{~mL}$ of $\mathrm{NaCl}$ solution (0.8\%) was added and vortexed for $1 \mathrm{~min}$; the solvent was decanted and collected. This step was repeated twice. The organic layer was dehydrated with anhydride sodium sulfate, filtered and evaporated under a gentle stream of nitrogen. Fatty acids of the residue were transesterified to their corresponding methyl ester and analyzed by gas chromatography as described above.

\section{Computed tomography study}

Computed tomography is a validated method for measuring VAF [18] and evaluating NAFLD [19]. In the present study, these measurements were obtained using a 64-slice scanner (Somatom Cardiac Sensation 64, Forchheim, Bavaria, Germany). To determine the liver: spleen attenuation ratio (L:SAR), a single-slice CT-scan was obtained at the level of T11-T12 or T12-L1. Fatty liver was defined as a liver/spleen attenuation ratio lower than 1.0, which has been proposed as threshold for detecting moderate or severe steatosis $(\geq 30 \%)$ by histology [19]. To calculate the amount of total abdominal fat (TAF) and VAF, a single-slice scan was performed at the level of L4-L5 and the area was expressed in square centimeters $\left(\mathrm{cm}^{2}\right)$. Subcutaneous abdominal fat (SAF) was calculated by subtracting the VAF from the TAF area.

\section{Statistical analysis}

Data are presented as mean \pm standard deviation, median (interquartile range) or prevalence. Comparisons were made by paired Student's t, Wilcoxon matched-pairs signed-rank or Chi-squared tests, as appropriate. $P$ values $<0.05$ were considered statistically significant. All the analyses were performed using SPSS for Windows (version 15.0; SPSS Chicago, II, USA).

\section{Results}

The study included 25 NAFLD patients; general characteristics are shown in Table 1. All patients concluded satisfactorily 8 weeks of chia intervention at $25 \mathrm{~g} /$ day, with a mean adherence of $93 \pm 8 \%$. The fatty acid characterization of chia revealed that ALA (65\%), linoleic $(20 \%)$, oleic $(6 \%)$, palmitic $(6 \%)$, and stearic $(3 \%)$ acids were the main components of the seed. After chia supplementation, an increase of plasma ALA (75\% [40125\%]) and higher dietary fiber consumption (55\% [1792\%]) was recorded (Table 2). At the beginning of the study, four subjects reported modest and transient gastrointestinal distress that did not merit their withdrawal from the study.

Table 1 General characteristics of studied patients, and abdominal body fat distribution at baseline and after 8 weeks of $25 \mathrm{~g} /$ day of chia consumption

\begin{tabular}{|c|c|c|c|}
\hline & \multirow[b]{2}{*}{ Basal } & \multicolumn{2}{|l|}{$n=25$} \\
\hline & & Post-chia & $P^{*}$ \\
\hline Age (years) & $58.0 \pm 7.7$ & & \\
\hline Men/women & $15 / 10$ & & \\
\hline Adherence (\%) & $93.0 \pm 8.0$ & & \\
\hline BMI $\left(\mathrm{kg} / \mathrm{m}^{2}\right)$ & $30.6 \pm 3.5$ & $29.9 \pm 3.5$ & $<0.0001$ \\
\hline WC (cm) & $100.4 \pm 9.8$ & $97.9 \pm 9.6$ & $<0.0001$ \\
\hline TAF $\left(\mathrm{cm}^{2}\right)$ & $538(433-631)$ & $501(410-568)$ & $<0.01$ \\
\hline $\operatorname{SAF}\left(\mathrm{cm}^{2}\right)$ & 317 (255-394) & $308(248-386)$ & $<0.05$ \\
\hline $\operatorname{VAF}\left(\mathrm{cm}^{2}\right)$ & 188 (164-230) & 180 (150-234) & $<0.05$ \\
\hline
\end{tabular}

Data are expressed as mean \pm standard deviation or median (interquartile range). BMI: body mass index, WC: waist circumference, TAF: total abdominal fat, SAF: subcutaneous abdominal fat, VAF: visceral abdominal fat. *paired Student's t-test or Wilcoxon matched-pairs signed-rank test, as correspond 
Table 2 Intake of macronutrients and plasma fatty acid composition, at baseline and after 8 weeks of $25 \mathrm{~g} /$ day of chia consumption

\begin{tabular}{|c|c|c|c|c|c|}
\hline & \multirow[b]{2}{*}{ Basal } & & \multicolumn{3}{|l|}{$n=25$} \\
\hline & & & Post-chia & & $P^{*}$ \\
\hline \multicolumn{6}{|c|}{ Macro nutrient intake } \\
\hline $\mathrm{kJ} /$ day & $6748 \pm 2030$ & & $7045 \pm 1628$ & & NS \\
\hline Fat $^{\mathrm{a}}(\%)$ & $26.3 \pm 5.6$ & & $30.4 \pm 4.4$ & & 0.001 \\
\hline Carbohydrate $^{a}(\%)$ & $51.1 \pm 7.2$ & & $48.8 \pm 5.5$ & & NS \\
\hline Protein $^{a}(\%)$ & $22.6 \pm 4.9$ & & $20.8 \pm 3.6$ & & NS \\
\hline Total fiber (g/day) & $17.3(13.8-33.4)$ & & $30.2(21.7-34.6)$ & & $<0.0001$ \\
\hline Plasma fatty acids & $\mu \mathrm{M}$ & $\%$ TFA & $\mu \mathrm{M}$ & $\%$ TFA & \\
\hline SFA & $3856(3078-4750)$ & 33.9 & $3563(2692-4341)$ & 33.0 & $<0.05$ \\
\hline MUFA & $2760(2258-3564)$ & 27.4 & $2635(1970-3508)$ & 26.3 & $<0.05$ \\
\hline PUFA $\omega-3$ & $270(173-360)$ & 2.8 & $328(233-499)$ & 3.6 & $<0.05$ \\
\hline PUFA $\omega-6$ & $3776(3226-4281)$ & 36.0 & $3631(2731-4249)$ & 37.0 & NS \\
\hline$\omega-6 / \omega-3$ & $13(11-18)$ & & $11(8-14)$ & & $<0.0001$ \\
\hline ALA & $80(52-112)$ & 0.8 & $145(104-255)$ & 1.4 & $<0.0001$ \\
\hline
\end{tabular}

Changes in the metabolic profile after chiaintervention were modest, with significant reduction in total cholesterol, non-HDL cholesterol, and FFA (Table 3). An additional analysis showed that, in subjects with initial high triglyceride concentrations $(\mathrm{TG} \geq 150$ $\mathrm{mg} / \mathrm{dL}, n=16)$, the improvement in FFA $(\mathrm{mmol} / \mathrm{L})$ was greater (basal: 0.74 [0.59-0.85], post-chia: 0.57 [0.470.64 ]; $P=0.02$ ). Regarding liver function tests, there were

Table 3 Biochemical parameters at baseline and after 8 weeks of $25 \mathrm{~g} /$ day of chia consumption

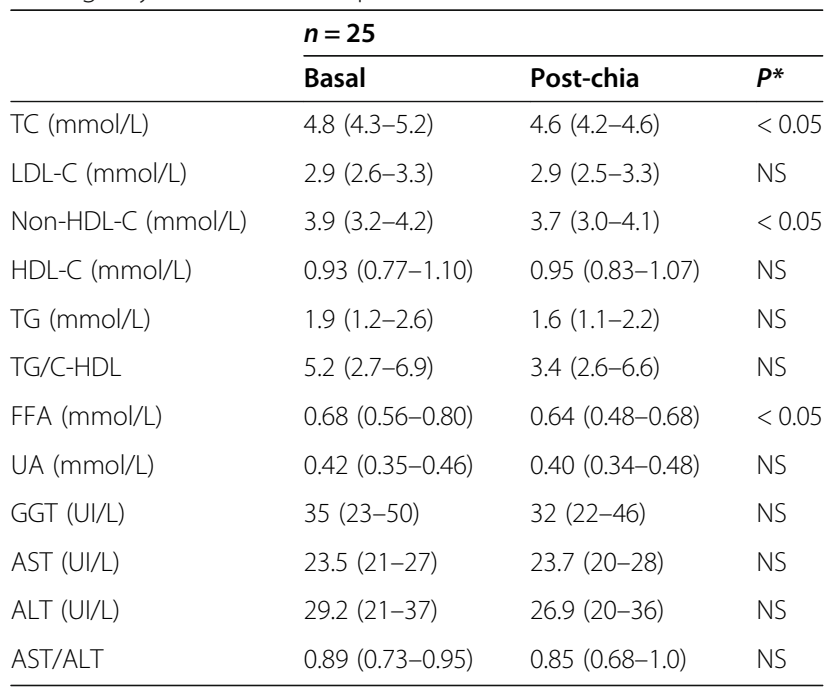

Data are expressed as median (interquartile range), TC: total cholesterol, LDL-C: low density lipoprotein cholesterol, non-HDL-C: non-high density lipoprotein cholesterol, HDL-C: high density lipoprotein cholesterol, TG: triglycerides, FFA: free fatty acids, UA: uric acid, GGT: gamma glutamyl transpeptidase, AST: aspartate aminotransferase, ALT: alanine aminotransferase, NS: non-significant. *Wilcoxon matched-pairs signed-rank test no differences in the median concentrations (Table 3), or in the prevalence of abnormal values (data not shown) after chia supplementation.

After 8 weeks of chia intervention, a significant body weight loss was observed (median $=-1.4 \%$ ), with consequent BMI and waist circumference reduction (Table 1). The analysis of the abdominal fat distribution revealed a reduction in TAF, principally due to a greater loss of VAF $(-9 \%)$ respect to the SAF deposit $(-5 \%)$. Furthermore, $52 \%$ of patients showed regression of the NAFLD (Fig. 2, panel A), with an increase of $22 \%$ in the liver:spleen attenuation ratio (Fig. 2, panel B). The improvement in the attenuation index was more marked in obese patients (24\%) as compared with those with overweight (9\%). This amelioration was concomitant to a higher increase in ALA and fiber consumption (panel C and D).

\section{Discussion}

The present study evaluated the effects on NAFLD of an isocaloric diet supplemented with $25 \mathrm{~g} /$ day of milled chia. To the best of our knowledge, the present study shows for the first time that milled chia reversed NAFLD in $52 \%$ of the treated patients. This was accompanied by decreases in BMI, waist circumference, and VAF reduction, particularly in obese subjects. These results suggest that milled chia intake could be an accessible therapeutic alternative for the control and prevention of NAFLD, and its main causes of morbidity and mortality (T2DM and $\mathrm{CAD})$.

Intervention studies with chia in humans are scarce and vary in the way of seed administration (whole seed soaked, milled, or incorporated into bread), duration of 


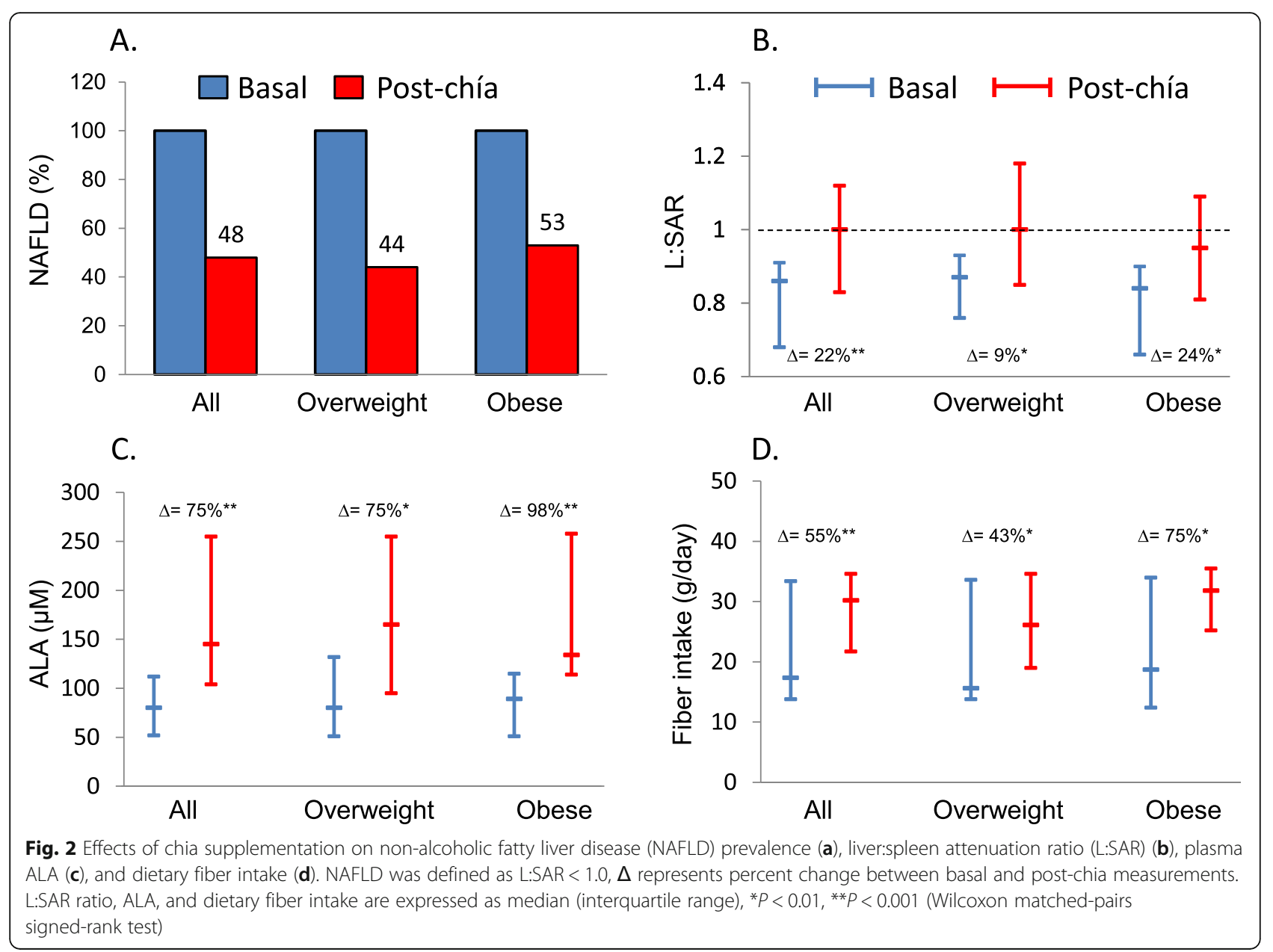

the intervention (weeks or months), type of basal diet (with or without caloric restriction), and characteristics of the included patients (apparently healthy or with diabetes) [14, 20-23]; besides, only few studies have analyzed plasma ALA increase after chia administration [14, 20]. Altogether these factors have given rise to controversies on possible chia beneficial effects. Nieman et al. proved the effect of whole [20] and milled chia seeds [14] on plasma ALA concentrations, finding that, independently of body weight, plasma ALA was increased by $138 \%$ when supplementing the habitual diet with $25 \mathrm{~g} /$ day of milled chia during 7 weeks [14]; whereas only $24 \%$ was increased when the whole seed soaked in water was consumed [20]. Considering these antecedents, in the present study, $25 \mathrm{~g} /$ day of milled chia was administered for 8 weeks. In line with Nieman et al., a 75\% (40-125\%) increase in ALA was reported. However, in contrast to the current and previous results [21, 22], Nieman et al. did not observe anthropometric or metabolic benefits after chia treatment [14, 20]. These inconsistencies could be explained by the clinical and metabolic characteristics of the study subjects. It is possible that the beneficial effects of chia are only evident when milled seed is administered to metabolically abnormal subjects, as Tavares-Toscano et al. reported [22].

In line with previous reports $[21,22]$, a significant increase in fiber (mean $=10 \mathrm{~g} /$ day) was found in the present study. It has been suggested that fiber forms a mechanical barrier in the gut that interferes with glucose and FFA absorption, in turn, promoting an increase in intraluminal viscosity, delayed intestinal transit, and increased production of the glucagon-like peptide-1 (GLP1 ), favoring the sensation of satiety $[23,24]$. These evidences support the weight loss observed in this and previous studies [22, 23]. Furthermore, the present results provide additional information by showing a reduction in VAF, which is considered a relevant fat deposit due to its association with insulin resistance and other cardiometabolic risk factors [25].

Previously, it had been suggested that a high omega-6: omega-3 index could be implicated in the etiopathogenesis of NAFLD [4, 26]. Evaluation of a dietary pattern study showed that patients with NAFLD had a high consumption of omega-6 polyunsaturated fatty acids [27]. Moreover, in animal models, reduction in the omega-6: 
omega-3 index decreases the intra-hepatic fat content [4, 28], independently of the bio-conversion of ALA to EPA and DHA [29]. These findings support the current observations regarding a significant reduction in the omega-6: omega- 3 index, accompanied by an amelioration in the liver:spleen attenuation ratio. These reductions are similar to those observed in a previous study using a Mediterranean diet [5]. Evidences in animal models suggest that the mechanisms involved in this NAFLD improvement include the modulating effect of ALA on the nuclear receptors SRBP-1c (sterols regulator) and the peroxisomes proliferator activated receptor alpha (PPAR $\alpha)$, which modulate de novo lipogenesis and beta-oxidation [9-11].

Therapeutic use of omega- 3 fatty acids for the management of NAFLD has gained interest, due to its potential antioxidant effect, among other benefits, since oxidation is part of the pathophysiology of fatty liver disease [3]. Moreover, a meta-analysis showed that dietary supplementation with animal sources of omega-3 fatty acids should be accompanied by antioxidants consumption, such as vitamin $\mathrm{E}$, as this kind of fatty acids are sensitive to oxidation. Additionally, a similar improvement of total antioxidant capacity was observed with plant sources of omega-3 fatty acids [30]. The beneficial effects of omega 3-rich seeds may be explained by their high antioxidants content. Particularly, chia seeds are rich in polyphenols and vitamin $\mathrm{E}$, molecules with a high antioxidant capacity [31]. Insulin-resistance and NAFLD animal model studies have shown that the administration of a chia-based diet, aside from decreasing de novo lipogenesis and improving beta-oxidation [9-11], restores the activity of some enzymes, including catalase and superoxide dismutase, that decrease the hepatic production of some oxidation and inflammation markers [32]. Hence, based on the present and previous studies, it is plausible to hypothesize that these mechanisms could act synergistically to reverse NAFLD. However, further studies are needed.

NAFLD has a multifactorial origin and a certain genetic susceptibility has been reported [2, 3]. Compared with carriers of the I148 allele, M148 allele carriers of the gene PNPLA3 have a greater susceptibility to develop NAFLD [2]. Studies evaluating both, the contribution of PNPLA3 polymorphism (I148M/ PNPLA3 rs738409) and therapeutic strategies on NAFLD are scarce. Nevertheless, it has been suggested that carriers of the I148 allele lose a greater proportion of hepatic fat in response to dipeptidyl peptidase-4 (DPP-4) inhibitors; whereas carriers of the M148 allele are more responsive to the effect of omega-3 fatty acids [33]. Chia supplementation offers a unique opportunity for NAFLD treatment, because in addition to its high omega- 3 content, it could increase GLP-1 due to its high viscosity fiber content [23]. The PNPLA3 polymorphism gene has been previously described in the GEA population [34]. The present study included three I/I, eleven I/M, and eleven $\mathrm{M} / \mathrm{M}$ genotyped subjects, an additional analyses showed that basal hepatic fat content (I/I homozygote: $0.78, \mathrm{I} / \mathrm{M}$ heterozygote: 0.89 , and $\mathrm{M} / \mathrm{M}$ homozygote: 0.84 ) and liver:spleen attenuation ratio improvement $(22,13$, and $24 \%$; respectively) were similar among different polymorphisms, suggesting that chia exerted a similar beneficial effect on the whole spectrum of NAFLD patients.

The effect of chia on glucose and lipid levels has been less studied. Nieman et al. did not observe improvements in these parameters when analyzing normolipidemic women [20]. However, Tavares-Toscano et al. [22] found improvements in the metabolic profile, but only in patients with abnormal biochemical parameters. In those subjects, a significant reduction occurred in TC and TG, as well as an increase in HDL-C levels. Our data showed a significant reduction in $\mathrm{TC}$ and nonHDL-C, and a non-statistically significant decrease in TG levels. FFA were also significantly reduced, particularly among subjects with initial high TG concentration (>150 mg/dL). These findings suggest an improvement in adipose tissue insulin sensitivity and reduction in de novo lipogenesis as a result of chia intake.

\section{Strengths and limitations}

The main strength of the present study was the tomographic analysis of abdominal fat, which allowed assessing chia's effect beyond body weight and its effect on fat depots with a greater pathophysiological transcendence. Based on previous studies, an adequate dose of the milled seed was administered, which allowed for a greater bioavailability of its nutrients and maximal increment in ALA; besides, adherence to treatment was higher than $90 \%$, and this was verified by quantifying ALA in plasma.

The most important limitation was the lack of a control group; however, previous studies agree about the difficulty of having an adequate placebo. In a placebocontrolled chia study, authors analyzed the blinded design in participants, finding that $60 \%$ of subjects on the placebo arm acknowledged being on placebo treatment [20]. On the other hand, controlled studies have used a fiber source as placebo, despite that it has not been elucidated whether ALA and fiber exert independent or synergistic beneficial effects. Studies with a cross-over design could be appropriate to confirm the present results. To avoid gastrointestinal adverse events, consumption of milled chia was recommended to occur from breakfast to lunch (always before 6:00 p.m); however, lipid absorption and metabolism may be higher during the beginning of the active/awake period [35]. Hence, a balance between these issues should be considered in further studies. Finally, an additional limitation is that 
NAFLD improvement was estimated through tomography. Although hepatic biopsy is the gold standard for this measurement, tomography has been shown to be a method that allows identifying intrahepatic fat deposits higher than than $30 \%$, with a sensitivity and specificity of $80 \%$ [36].

\section{Conclusions}

The results of the present study show that $25 \mathrm{~g} /$ day of milled chia ameliorates NAFLD. Due to its composition, chia could be an accessible vegetal source of omega-3 fatty acids, antioxidants, and fiber. These phytochemicals have the potential to prevent the appearance of metabolic abnormalities, advanced stages of NAFLD, and development of T2DM and CAD in NAFLD patients. Functional foods are suggested as part of innovative therapies for the treatment of cardiometabolic diseases. Although findings of the present study expand this information, more studies are needed to consolidate these nutriments as therapeutical alternatives.

\section{Abbreviations}

NAFLD: non-alcoholic fatty liver disease; ALA: alpha linolenic acid; EPA: eicosapentaenoic acid; DHA: docosahexaenoic acid; BMl: body mass index; VAF: visceral abdominal fat; SAF: subcutaneous abdominal fat; TAF: total abdominal fat; L:SAR: liver:spleen attenuation ratio; FFA: free fatty acids; T2DM: type 2 diabetes mellitus; CAD: coronary artery disease; HOMAIR: homeostasis model assessment for insulin resistance; GEA: Genetics of the Atherosclerotic Disease study

\section{Acknowledgments}

Authors thank the staff of the Endocrinology and Tomography Departments of the Instituto Nacional de Cardiología Ignacio Chávez, as well as the participants of the study.

\section{Conflict of interest}

None.

\section{Authors' contributions}

A.M.U. and J.G.J.R. designed and supervised the conduction of the study, and wrote the first draft of the manuscript; A.R.L.U. and M.C.G.S. conducted the research, E.J.G. performed the statistical analyses; M.E.H., R.P.S. and L.V.M. critically reviewed and commented the manuscript. All the authors read and approved the final version of the manuscript.

\section{Funding}

This research was partially financed by the Instituto Nacional de Cardiología Ignacio Chávez and the Consejo Nacional de Ciencia y Tecnología (Project No. SALUD-2016-01-272502)

\section{Availability of data and materials}

According to the policy of BMC, we would like to inform that all the datasets analyzed during the current study are available from the corresponding author upon reasonable request.

\section{Ethics approval and consent to participate}

The experimental protocol complied with the ethical guidelines of the 1975 Declaration of Helsinki and was approved by the Research and Ethics Committee of the Instituto Nacional de Cardiología Ignacio Chavez (No. 16980), and was retrospectively registered at clinical trials.gov (NCT03942822). Candidates that accepted to participate in the study provided written informed consent for the study prior to completing any assessments.

\section{Consent for publication}

Does not apply.

\section{Competing interests}

The authors declare that they have no competing interests.

\section{Author details}

${ }^{1}$ Departamento de Endocrinología, Juan Badiano 1, Col. Sección XVI, Tlalpan, Mexico City, Mexico. ${ }^{2}$ Departamento de Biomedicina Cardiovascular, Juan Badiano 1, Col. Sección XVI, Tlalpan, Mexico City, Mexico. ${ }^{3}$ Departamento de Farmacología, Juan Badiano 1, Col. Sección XVI, Tlalpan, Mexico City, Mexico.

Received: 19 June 2019 Accepted: 12 May 2020

Published online: 19 May 2020

\section{References}

1. Ma J, Hwang SJ, Pedley A, Massaro JM, Hoffmann U, Chung RT, et al. Bidirectional analysis between fatty liver and cardiovascular disease risk factors. J Hepatol. 2017;66:390-7. https://doi.org/10.1016/j.jhep.2016.09.022.

2. Gastaldelli A. Insulin resistance and reduced metabolic flexibility: cause or consequence of NAFLD? Clin Sci (Lond). 2017; 131: 2701-4. doi: https://doi. org/10.1042/CS20170987.

3. Romero-Gómez M, Zelber-Sagi S, Trenell M. Treatment of NAFLD with diet, physical activity and exercise. J Hepatol. 2017;67:829-46. https://doi.org/10. 1016/j.jhep.2017.05.016.

4. Jeyapal S, Kona SR, Mullapudi SV, Putcha UK, Gurumurthy P, Ibrahim A. Substitution of linoleic acid with a-linolenic acid or long chain n-3 polyunsaturated fatty acid prevents Western diet induced nonalcoholic steatohepatitis. Sci Rep. 2018;19:10953. https://doi.org/10.1038/s41598-01829222-y.

5. Properzi C, O'Sullivan TA, Sherriff JL, Ching HL, Jeffrey GP, Buckley RF, et al. Ad libitum Mediterranean and low-fat diets both significantly reduce hepatic Steatosis: a randomized controlled trial. Hepatology. 2018;68:174154. https://doi.org/10.1002/hep.30076

6. Silva Figueiredo P, Inada AC, Ribeiro Fernandes M, Granja Arakaki D, Freitas KC, Avellaneda Guimarães RC, et al. An overview of novel dietary supplements and food ingredients in patients with metabolic syndrome and non-alcoholic fatty liver disease. Molecules. 2018;23:877. https://doi.org/ 10.3390/molecules23040877.

7. Darvish Damavandi R, Mousavi SN, Shidfar F, Mohammadi V, Rajab A, Hosseini S, et al. Effects of daily consumption of cashews on oxidative stress and Atherogenic indices in patients with type 2 diabetes: a randomized. Controlled-Feeding Trial Int J Endocrinol Metab. 2019;17:e70744. https://doi. org/10.5812/ijem.70744.

8. Akbari-Fakhrabadi M, Heshmati J, Sepidarkish M, Shidfar F. Effect of sumac (Rhus Coriaria) on blood lipids: a systematic review and meta-analysis. Complement Ther Med. 2018;40:8-12. https:/doi.org/10.1016/..ctim.2018.07.001.

9. Oliva ME, Ferreira MR, Chicco A, Lombardo YB. Dietary Salba (Salvia hispanica L) seed rich in a-linolenic acid improves adipose tissue dysfunction and the altered skeletal muscle glucose and lipid metabolism in dyslipidemic insulin-resistant rats. Prostaglandins Leukot Essent Fatty Acids. 2013;89:279-89. https://doi.org/10.1016/j.plefa.2013.09.010.

10. Montes Chañi EM, Pacheco SOS, Martínez GA, Freitas MR, Ivona JG, Ivona JA, et al. Long-term dietary intake of chia seed is associated with increased bone mineral content and improved hepatic and intestinal morphology in Sprague-Dawley rats. Nutrients. 2018;10:E922. https://doi.org/10.3390/ nu10070922.

11. Rossi AS, Oliva ME, Ferreira MR, Chicco A, Lombardo YB. Dietary chia seed induced changes in hepatic transcription factors and their target lipogenic and oxidative enzyme activities in dyslipidaemic insulin-resistant rats. $\mathrm{Br} J$ Nutr. 2013;109:1617-27. https://doi.org/10.1017/S0007114512003558.

12. Martínez-Alvarado M del R, Juárez-Rojas JG, Medina-Urrutia AX, CardosoSaldaña GC, González-Salazar M del C, Posadas-Sánchez R, et al. Association of fatty liver with cardiovascular risk factors and subclinical atherosclerosis in a Mexican population Rev Invest Clin 2014; 66: 407-414. PubMed PMID: 256 95383.

13. Salvador Castell G, Serra-Majem L, Ribas-Barba L. What and how much do we eat? 24-hour dietary recall method. Nutr Hosp. 2015; Suppl 3:46-48. doi: https://doi.org/10.3305/nh.2015.31.sup3.8750.

14. Jin F, Nieman DC, Sha W, Xie G, Qiu Y, Jia W. Supplementation of milled chia seeds increases plasma ALA and EPA in postmenopausal women. Plant Foods Hum Nutr. 2012;67:105-10. https:/doi.org/10.1007/s11130-012-0286-0.

15. DeLong DM, DeLong ER, Wood PD, Lippel K, Rifkind BM. A comparison of methods for the estimation of plasma low- and very low-density lipoprotein 
cholesterol. The lipid research clinics prevalence study. J Am Med Assoc. 1986;256:2372-7. https://doi.org/10.1001/jama.1986.03380170088024.

16. Folch J, Lees M, Sloane Stanley GH. A simple method for the isolation and purification of total lipides from animal tissues. J Biol Chem, 1957; 226: 497509. PubMed PMID: 13428781.

17. Association of Official Analytical Chemists (AOAC). Official methods of analysis. 15th ed. Arlington, VA: AOAC; 1990

18. Kvist H, Chowdhury B, Grangård U, Tylén U, Sjöström L. Total and visceral adipose-tissue volumes derived from measurements with computed tomography in adult men and women: predictive equations. Am J Clin Nutr 1988; 48: 1351-1313. PubMed PMID: 3202084.

19. McKimmie RL, Daniel KR, Carr JJ, Bowden DW, Freedman BI, Register TC et al. Hepatic steatosis and subclinical cardiovascular disease in a cohort enriched for type 2 diabetes: the diabetes heart study. Am J Gastroenterol. 2008:103:3029-35. https://doi.org/10.1111/j.1572-0241.2008.02188.x.

20. Nieman DC, Cayea EJ, Austin MD, Henson DA, McAnulty SR, Jin F. Chia seed does not promote weight loss or alter disease risk factors in overweight adults. Nutr Res. 2009;29:414-8. https://doi.org/10.1016/j.nutres.2009.05.011.

21. Vuksan V, Jenkins AL, Brissette C, Choleva L, Jovanovski E, Gibbs AL, et al. Salba-chia (Salvia hispanica $\mathrm{L}$.) in the treatment of overweight and obese patients with type 2 diabetes: A double-blind randomized controlled trial. Nutr Metab Cardiovasc Dis. 2017; 27: 138-46. doi: https://doi.org/10.1016/j. numecd.2016.11.124

22. Tavares Toscano L, Tavares Toscano L, Leite Tavares R, da Oliveira Silva CS, Silva AS. Chia induces clinically discrete weight loss and improves lipid profile only in altered previous values. Nutr Hosp. 2014;31:1176-82. https:// doi.org/10.3305/nh.2015.31.3.8242.

23. Vuksan V, Choleva L, Jovanovski E, Jenkins AL, Au-Yeung F, Dias AG, et al. Comparison of flax (Linum usitatissimum) and Salba-chia (Salvia hispanica L. ) seeds on postprandial glycemia and satiety in healthy individuals: a randomized, controlled, crossover study. Eur J Clin Nutr. 2017;71:234-8. https://doi.org/10.1038/ejcn.2016.148.

24. Bozzetto L, Costabile G, Della Pepa G, Ciciola P, Vetrani C, Vitale M, et al. Dietary Fibre as a Unifying Remedy for the Whole Spectrum of ObesityAssociated Cardiovascular Risk. Nutrients. 2018; 10: pii: E943. doi: https://doi. org/10.3390/nu10070943

25. Smith JD, Borel AL, Nazare JA, Haffner SM, Balkau B, Ross R, et al. Visceral adipose tissue indicates the severity of cardiometabolic risk in patients with and without type 2 diabetes: results from the INSPIRE ME IAA study. J Clin Endocrinol Metab. 2012;97:1517-25. https://doi.org/10.1210/jc.2011-2550.

26. Simopoulos AP. The importance of the omega-6/omega-3 fatty acid ratio in cardiovascular disease and other chronic diseases. Exp Biol Med. 2008;233: 674-88. https://doi.org/10.3181/0711-MR-311.

27. Eslamparast T, Tandon P, Raman M. Dietary Composition Independent of Weight Loss in the Management of Non-Alcoholic Fatty Liver Disease. Nutrients. 2017; 9: pii:800. doi: https://doi.org/10.3390/nu9080800.

28. Han H, Qiu F, Zhao H, Tang H, Li X, Shi D. Dietary flaxseed oil prevents Western-type diet-induced nonalcoholic fatty liver disease in Apolipoprotein-E knockout mice. Oxidative Med Cell Longev. 2017;3256241. https://doi.org/10.1155/2017/3256241

29. Monteiro J, Askarian F, Nakamura MT, Moghadasian MH, Ma DW. Oils rich in a-linolenic acid independently protect against characteristics of fatty liver disease in the $\Delta 6$-desaturase null mouse. Can J Physiol Pharmacol. 2013;91: 469-79. https://doi.org/10.1139/cjpp-2012-0308.

30. Sepidarkish M, Akbari-Fakhrabadi M, Daneshzad E, Yavari M, Rezaeinejad M, Morvaridzadeh M, et al. Effect of omega-3 fatty acid plus vitamin E cosupplementation on oxidative stress parameters: a systematic review and meta-analysis. Clin Nutr. 2020 Apr;39(4):1019-25. https://doi.org/10.1016/j. clnu.2019.05.004

31. Marcinek K, Krejpcio Z. Chia seeds (Salvia hispanica): health promoting properties and therapeutic applications - a review. Rocz Panstw Zakl Hig. 2017:68(2):123-9. 28646829.

32. Ferreira MR, Alvarez SM, Illesca P, Giménez MS, Lombardo YB. Dietary Salba (Salvia hispanica L.) ameliorates the adipose tissue dysfunction of dyslipemic insulin-resistant rats through mechanisms involving oxidative stress, inflammatory cytokines and peroxisome proliferator-activated receptor $\gamma$. Eur J Nutr. 2018 Feb;57(1):83-94. https://doi.org/10.1007/s00394-016-1299-5.

33. Wang JZ, Cao HX, Chen JN, Pan Q. PNPLA3 rs738409 underlies treatment response in nonalcoholic fatty liver disease. World J Clin Cases. 2018; 6: 167-75. doi: https://doi.org/10.12998/wjcc.v6.i8.167.
34. Posadas-Sánchez R, López-Uribe ÁR, Posadas-Romero C, Pérez-Hernández N, Rodríguez-Pérez JM, Ocampo-Arcos WA, et al. Association of the I148M/ PNPLA3 (rs738409) polymorphism with premature coronary artery disease, fatty liver, and insulin resistance in type 2 diabetic patients and healthy controls. The GEA study Immunobiology. 2017;222:960-6. https://doi.org/10. 1016/j.jimbio.2016.08.008.

35. Bray MS, Young ME. Regulation of fatty acid metabolism by cell autonomous circadian clocks: time to fatten up on information? J Biol Chem. 2011;286:11883-9. https://doi.org/10.1074/jbc. R110.214643.

36. Ataseven $\mathrm{H}$, Yildirim MH, Yalniz M, Bahcecioglu IH, Celebi S, Ozercan IH. The value of ultrasonography and computerized tomography in estimating the histopathological severity of nonalcoholic steatohepatitis. Acta Gastroenterol Belg 2005; 68: 221-225. PubMed PMID: 16013637.

\section{Publisher's Note}

Springer Nature remains neutral with regard to jurisdictional claims in published maps and institutional affiliations.

Ready to submit your research? Choose BMC and benefit from:

- fast, convenient online submission

- thorough peer review by experienced researchers in your field

- rapid publication on acceptance

- support for research data, including large and complex data types

- gold Open Access which fosters wider collaboration and increased citations

- maximum visibility for your research: over $100 \mathrm{M}$ website views per year

At $\mathrm{BMC}$, research is always in progress.

Learn more biomedcentral.com/submissions 